\title{
The Dynamics and Harvesting Effect Population One Prey Two Predator with Schooling Behavior
}

\author{
Rian Ade Pratama *, Maria F. V. Ruslau, and Dessy Rizki Suryani \\ Department of Mathematics Education, Faculty of Teacher Training and Education, Musamus University, Jl. Kamizaun Mopah Lama \\ Merauke 99600, Indonesia.
}

\begin{abstract}
This paper, the model considered is a predator-prey model for an exploited population. Predator and prey species in the offered concept have schooling characteristics. The characteristics of schooling are very similar to behavior in natural ecosystems. Based on the equilibrium analysis obtained five equilibrium points. The equilibrium point is the only one that satisfies the equilibrium model based on the Routh-Hurwitz criteria. Meanwhile, harvesting effort using the chosen equilibrium point was also calculated in the study. The principle of bionomic equilibrium is a method of showing the results of harvesting as a parameter control. Numerical simulations are also carried tor to validate the findings in the research discussion. Parameters taken from assumptions and references become important and critical references. Trajectories show a population of prey and predator one population that continues to be sustainable despite harvesting efforts. Meanwhile, different trajectories are shown by the population of two predators, which experienced a decrease in population growth. Harvesting attempts carried out on predator two continuously until a certain time will result in serious extinctions.
\end{abstract}

Keywords: predator-prey, schooling, stability, harvesting.

\section{Introduction}

Ecosystem life in nature is very dependent on human activities in survival. Interdependence is a characteristic of the social life of living things. Many types of living things have behaviors to help, protect and defend themselves. Living in groups in an ecosystem of living things is often encountered. As in many fish species that live their underwater life in groups. Group life provides many benefits to the survival of these species [1]. The higher survival of species, ease of finding a mate to breed, reduced predatory attack, increased success in foraging, protection from weather and natural disasters are examples of the benefits of living in groups [2].

In marine ecosystems, fish and micro-organisms apply a lot of group life to the survival of species. The focus of this article is on the unit characteristics of marine ecosystems such as fish. The behavior that occurs in group life has two characteristics, the first is called soaling and the second is schooling [3]. Soaling is a characteristic of species that have close relationships and remain connected to each other even when group members move independently [4]. Meanwhile, for schooling characteristics, all members of the group move in a directed and coordinated manner.

Species with schooling characteristics usually have similarities in terms of moving speed, family type, size, response function, and food [5]. Species with a group life will continue to exhibit soaling or schooling behavior. Species life with schooling characteristics will continue as long as the group is still solid and strong. The behavior of mating, preying, surviving, laying eggs or breeding is the right reason for survival in this type of species. When moving or migrating these species can form ovals, squares, lines and other forms of amoeba [6].

In the species interaction activities that occur, it is beneficial or detrimental to the species involved in the interaction. The influence on the predator-prey relationship is very important in the interactions that occur [7]. For example, in the prey business, developing methods used to avoid prey attacks. The statement that prey is always threatened by predators is not always true, but the interaction of the two will provide benefits for each species. This predator-prey relationship will play an important role in maintaining the ecological balance of natural life [8].

The predatory-prey mathematical modeling was first developed by Lotka and Volterra. The development of the predator-prey model continues to progress rapidly, to perfect the mathematical model. The better the assumptions used, the better the mathematical model that is formed [9]. The assumptions in the mathematical model have a huge influence on the goals to be achieved [10]. In modeling in this study members or individuals of predator and prey populations can live independently.

\footnotetext{
* Corresponding author: pratama@unmus.ac.id
} 
Each predator can interact with any type of prey at any time. The magnitude of the interaction rate that occurs will be proportional to the growth rate of the two populations.

Many types of predator-prey fish have mathematical models in marine ecosystems. Broadly speaking, fish living in groups are often referred to as fish pelagic. There are two types of pelagic fish in waters Indonesian, namely pelagic large and pelagic small. The large pelagic fish such as Tengiri (Scomberomorus guttatus and Scomberomorus commerson) and Tongkol (Euthynnus affinis). Meanwhile, small pelagic fish in Indonesian waters such as mackerel (Rastrelliger kanagurta and Rastrelliger brachysoma), Teri (Stolephorus indicus), Ekor Kuning (Caesio cuning), and Belanak (Crenimugil crenilabis) [11]. Pelagic fish in Indonesian waters are mostly harvested by fishermen. Meanwhile, many fish of the pelagic species have been cultivated by fish farmers. The limitation of the fishing area takes into account the types of fish in open waters and non-fish in fishermen's cultivation products.

The development of mathematical models of populations of marine species that live in groups has also been developed by recent studies. If the fish population is large, then a model that takes into account the characteristics of the group will be more suitable for natural conditions, when compared to one that ignores the characteristics of the group [12]. These assumptions have become the basis of the research in this article. Predator-prey population model with two predators and one prey species. Population life in predators and in prey adopts herd characteristics. These two species live in groups in one wide carrying capacity. The principle of harvesting is done because marine species provide many benefits to humans [13]. The benefits obtained economically and human health form the basis for harvesting in marine ecosystems. Harvesting systems that are carried out using bionomic equilibrium, will consider the biological balance and economic balance [14]. Harvesting is carried out by considering the bionomic balance system, for sustainable harvesting efforts [15].

\section{Mathematics model predator-prey with schooling behavior}

The predatory prey model in this study uses logistical growth. The assumption used in logistical growth is the number of population that continues to grow to infinity as long as the predator is controlled during predation [16]. The number of predators is also very dependent on the presence of their surviving prey. The logistic model equation is given by

$$
\begin{aligned}
& \frac{d x}{d t}=x(a-b y), \\
& \frac{d y}{d t}=y(d x-c) .
\end{aligned}
$$

The time $t$, the variable $x(t)$ shows the prey population density and $y(t)$ shows the population density of the predator. For variables $a, b, c$ and $d$, respectively, are the growth of the prey population, the predation of the predator, the death rate of the predator, and the growth rate of the predator. All are eligible for $a, b, c, d>0$, because each population has the potential to continue reproducing.

Another form of logistic growth model also gives the same assumption of logistic growth above about carrying capacity, shown as

$$
\frac{d x}{d t}=\rho x\left(1 \frac{x}{k}\right)
$$

The variable $\rho$ represents the intrinsic logistic growth rate and $k$ represents the carrying capacity at the site where the species lives. Carrying capacity provides an overview of the carrying capacity such as the area to live, the number of food sources, and natural nutrients for natural species life. If its carrying capacity is limited, it is clear that the growth will go to a saturation point to grow. Meanwhile, the form of interaction $-\frac{\rho x^{2}}{k}$ describes the intraspecific competition that occurs. Intraspecific competition is an interaction between species. This can happen because each individual competes for sustainable survival.

The assumptions used for predator and prey, individually, both predator and prey live independently. This assumption is used because predators do not have a specified time to prey on prey. This shows an interaction proportional to the total density in the two populations. If the predatory population is schooling for prey, the predators at the edge of schooling will get the best predation results. Prey predator interactions must remain proportional to the number of prey population growth and the square root of the number of predator population growth. Likewise, it happened to the prey that formed the schooling, in the prediction interaction the most disadvantaged prey was the prey that was in the most marginal area [17].

The most interesting ideas are the population densities of predators and prey. The variable $N$ represents the density of a schooling species and the species occupies a particular area that is the area $K$. This problem shows that the number of the outer individuals of the species group is proportional to the circumference of the area the species is present in. Therefore, the circumference of the area is proportional to $\sqrt{K}$. For the species population represented by $N$ calculated using two dimensions, then will show the number of species in the schooling edge area [18]. In this study, it is assumed that predators and prey have the characteristics of schooling behavior. The interactions that occur between predatory schooling and prey schooling will adopt the assumptions that have been described.

The interaction that occurs when the predation process takes place is at the edge of the meeting between the two species. The interaction between predator and prey only occurs in the margins of the two populations. Both predator population density and prey population density are proportional to the product of the square root of the density of the two interacting populations [19]. It is assumed that the number of predators in this model is two predators that predate one prey. The mathematical model formed from the interaction of the two is $a \sqrt{x} \sqrt{y}$ and $b \sqrt{x} \sqrt{z}$, where $a$ and $b$ are the predatory rates of 
predator one and predator two. Another assumption used in this model is that the survival of predator predation depends only on one species of prey.

Furthermore, the last assumption used in this research is the existence of a harvesting business that is carried out two prey and predator. Harvesting business is carried out selectively on two populations of species. The fishing effort rate equation for prey and predator is $q_{1} E_{1} x$ and $q_{2} E_{2} Z$, where and $q_{2}$ are the coefficients of the population of prey and predator species [20]. The mathematical model formed from these assumptions can be seen as follows:

$$
\begin{aligned}
& \frac{d x}{d t}=x \rho\left(1-\frac{x}{k}\right)-(a \sqrt{y}-b \sqrt{z}) \sqrt{x}-q_{1} E_{1} x \\
& \frac{d y}{d t}=c \sqrt{x} \sqrt{y}-\delta_{1} y \\
& \frac{d z}{d t}=d \sqrt{x} \sqrt{z}-\delta_{2} z-q_{2} E_{2} z
\end{aligned}
$$

where the initial value is

$x(0)>0 ; y(0) \geq 0 ; z(0) \geq 0$

parameters selected in the mathematical modeling of the population are non-negative. The parameters $\rho$ and $k$ are the prey's intrinsic growth rate and carrying capacity, respectively. For parameters $c$ and $d$, respectively, the conversion rates for predator one and predator two.

\section{Equilibrium}

The equilibrium point of the model (2.3) is described in detail in this section. Based on the analysis that has been carried out on the equilibrium model, there are five equilibrium points in this model, including, $T_{2}=$ $(K, 0.0), T_{3}=\left(x_{1}, y_{1}, z_{1}\right), T_{4}=\left(x_{2}, y_{2}, z_{2}\right)$ and $T_{5}=$ $\left(x_{3}, y_{3}, z_{3}\right)$.

where

$K=k_{1}$,

$x_{1}=-\frac{k_{1}\left(a c-\rho \delta_{1}\right)}{\rho \delta_{1}}$,

$y_{1}=-\frac{k_{1} c^{2}\left(a c-\rho \delta_{1}\right)}{\rho\left(\delta_{1}\right)^{3}}$,

$x_{2}=-\frac{k_{1}\left(b d-\rho \delta_{2}\right)}{\rho \delta_{2}}$,

$z_{2}=-\frac{k_{1} d^{2}\left(b d-\rho \delta_{2}\right)}{\rho\left(\delta_{2}\right)^{3}}$

$x_{3}=-\frac{k_{1}\left(a c \delta_{2}+b d \delta_{1}-\rho \delta_{1} \delta_{2}\right)}{\rho \delta_{1} \delta_{2}}$,

$y_{3}=-\frac{k_{1} c^{2}\left(a c \delta_{2}+b d \delta_{1}-\rho \delta_{1} \delta_{2}\right)}{\rho\left(\delta_{1}\right)^{3} \delta_{2}}$,

$z_{3}=-\frac{k_{1} d^{2}\left(a c \delta_{2}+b d \delta_{1}-\rho \delta_{1} \delta_{2}\right)}{\rho\left(\delta_{2}\right)^{3} \delta_{1}}$.

The positive equilibrium point in a model (2.3) will be taken to test the stability of the model. Based on the research analysis on the equilibrium point $T_{5}=$ $\left(x_{3}, y_{3}, z_{3}\right)$ fulfills the positive form. Furthermore, the positive equilibrium point becomes the test material for stability in the Jacobian Matrix, with the criteria Routh-
Hurwitz. The following is the Jacobian Matrix of equilibrium points:

$J_{\text {cob }}=\left[\begin{array}{ccc}J_{11} & J_{12} & J_{13} \\ J_{21} & J_{22} & 0 \\ J_{31} & 0 & J_{33}\end{array}\right]$

where

$J_{11}$

$=-\frac{1}{2} \frac{a \delta_{1} \delta_{2} \sqrt{A}+\left(\left(-4 a c+2 \rho \delta_{1}\right) \delta_{2}-4 b d \delta_{1}\right) \sqrt{B}}{\sqrt{B} \delta_{1} \delta_{2}}$

$+\frac{b \delta_{1} \delta_{2} \sqrt{C}}{\sqrt{B} \delta_{1} \delta_{2}}$

$J_{12}=-\frac{1}{2} \frac{a \sqrt{B}}{\sqrt{A}}$

$J_{13}=-\frac{1}{2} \frac{b \sqrt{B}}{\sqrt{C}}$

$J_{21}=\frac{1}{2} \frac{c \sqrt{A}}{\sqrt{B}}$,

$J_{22}=\frac{1}{2} \frac{c \sqrt{B}}{\sqrt{A}}-\delta_{1}$,

$J_{31}=\frac{1}{2} \frac{d \sqrt{A}}{\sqrt{B}}$

$J_{33}=\frac{1}{2} \frac{d \sqrt{B}}{\sqrt{A}}-\delta_{2}$

The equation for the Jacobian characteristics of the Equilibrium point $T_{5}=\left(x_{3}, y_{3}, z_{3}\right)$ is as follows

$$
\lambda^{3}+N_{1} \lambda^{2}+N_{3} \lambda+N_{4}=0,
$$

For all the coefficient values of these characteristic equations meet the criteria to be the equation Jacobian characteristics, where $N_{1}>0, N_{2}>0, N_{3}>0$ and for $N_{1} N_{2} N_{3}-N_{3}^{2}-N_{2}^{2} N_{4}>0$. The similarity of these characteristics meets the requirements of the criteria Routh-Hurwitz and meets stability.

\section{Optimal Harvesting}

The harvesting business carried out in model (2.3) is harvesting which is carried out on the prey population $q_{1} E_{1}$ and the predatory population of two $q_{2} E_{2}$. This harvesting business uses bionomic balance in its calculations. The profit function is also taken into account in the harvesting business model. The profit function specifically shows the economic balance. Economic balance is achieved if the total income (TR) is obtained from the sale of the population stock which is harvested is proportional to the total cost (TC) of the effort done in population harvesting. The general profit function is as follows:

$$
\begin{aligned}
& \pi\left(E_{x}, E_{y}\right)=p_{x} E_{x} x+p_{y} E_{y} y-c_{f} \\
& -c_{x} E_{x}-c_{y} E_{y}
\end{aligned}
$$

The equilibrium point that satisfies the harvesting process is $T_{5}=\left(x_{3}, y_{3}, z_{3}\right)$. Harvesting was carried out on the population of prey $x_{3}$ and predator $z_{3}$. The equilibrium point will be substituted in equation (4.1), so that the profit function becomes:

$$
\begin{aligned}
& \pi\left(E_{1}, E_{2}\right)=p_{1} E_{1} x+p_{2} E_{2} y \\
& -c_{1} E_{1}-c_{2} E_{2}
\end{aligned}
$$

The critical point will be obtained for $E_{1}$ and $E_{2}$ which will reflect the value that the harvest can do. 


$$
\begin{aligned}
& \pi\left(E_{1}, E_{2}\right)=p_{1} E_{1} x_{3}+p_{2} E_{2} y_{3}-c_{1} E_{1}-c_{2} E_{2}, \\
& \pi\left(E_{1}, E_{2}\right) \\
& =-\frac{m E_{1}\left(E_{1} E_{2} n+l E_{1}-E_{2}+E_{1}+g\right)}{w E_{2}+r} \\
& -\frac{v E_{2}\left(E_{1} E_{2} n+l E_{1}-E_{2}+E_{1}+g\right)}{E_{2}{ }^{3}+E_{2}{ }^{2}+E_{2}+q}-c_{1} E_{1}-c_{2} E_{2},
\end{aligned}
$$

where

$$
\begin{aligned}
m=p 1 k_{1}, n= & \delta_{1} q_{1} q_{3}, l=a c q_{3}, h=\rho \delta_{1} q_{3}, k \\
& =\delta_{1} \delta_{2} q_{1}, g \\
& =a c \delta_{2}+b d \delta_{1}-\rho \delta_{1} \delta_{2}, v \\
& =p 3 k_{1} d^{2}, r=\rho \delta_{1} \delta_{2}, f \\
& =\rho \delta_{1} \delta_{2}{ }^{3}, j=3 \rho \delta_{1} \delta_{2} q_{3}{ }^{2}, p \\
& =3 \rho \delta_{1} \delta_{2}{ }^{2} q_{3}, q=\rho \delta_{1} \delta_{2}{ }^{3}
\end{aligned}
$$

It can be seen explicitly that the profit function $\pi\left(E_{1}, E_{2}\right)$ are negative functions, but mathematically it has been proven that the profit function is positive.

\section{Numerical Simulation Models}

Simulation model process (2.3) without harvesting, take the following variable parameters $\rho=1.5, k_{1}=$ $100, a=0.002, b=0.04, c=0.002, d=$ $0.04, \delta_{1}=0.0008, \delta_{2}=0.04, E_{1}=0$ and $E_{2}=0$. These parameters give a positive equilibrium, namely $T_{5}=\left(x_{3}, y_{3}, z_{3}\right)=(97,606.25,97)$. The equation for the characteristics of the Jacobian matrix obtained is $f(\lambda)=\lambda^{3}+1.452900000 \lambda^{2}+0.02963 \lambda+$

0.00001164 . from the form of the characteristic equation, the fulfillment of the Routh-Hurwitz criteria will be shown. So that the eigenvalues of the RouthHurwitz criteria are

$$
\begin{aligned}
& \lambda_{1}=-1.43221605880801 \\
& \lambda_{2}=-0.0202832527277183 \\
& \lambda_{3}=-0.000400688464175506
\end{aligned}
$$

All eigenvalues show real and negative results, this results in the equilibrium point $T_{5}=\left(x_{3}, y_{3}, z_{3}\right)$ is locally asymptotically stable. This mathematics shows that the prey and predator populations will survive for a long time.

The second simulation has performed model (2.3) with harvesting effort, with the following parameters $\rho=1.5, k_{1}=100, a=0.002, b=0.04, c=$ $0.002, d=0.04, \delta_{1}=0.0008, \delta_{2}=0.04, q_{1}=$ $1, q_{2}=1, p_{1}=100, p_{2}=100, c_{1}=50$ and $c_{2}=50$. We get an equilibrium point $T_{5}=\left(x_{3}, y_{3}, z_{3}\right)$ : $x_{3}$

$$
\begin{aligned}
& =\left(-\frac{0.3333333333\left(5000 E_{1} E_{2}+200 E_{1}-7475 E_{2}-291\right)}{25 E_{2}+1}\right), \\
& y_{3} \\
& =\left(-\frac{2.083333333\left(5000 E_{1} E_{2}+200 E_{1}-7475 E_{2}-291\right)}{25 E_{2}+1}\right), \\
& z_{3} \\
& =\left(-\frac{0.3333333333\left(5000 E_{1} E_{2}+200 E_{1}-7475 E_{2}-291\right)}{15625 E_{2}{ }^{3}+1975 E_{2}{ }^{2}+75 E_{2}+1}\right) .
\end{aligned}
$$

From the equilibrium point, the profit function (4.2) is obtained

$$
\pi\left(E_{1}, E_{2}\right)=100 E_{1} x_{3}+100 E_{2} y_{3}-50 E_{1}-50 E_{2},
$$

The critical value of $E_{1}$ and $E_{2}$ obtained from the first partial derivative is $E_{1}=0.7374408402$ and $E_{2}=$ 0.1917101576 . Each of these harvesting efforts will be a support for obtaining a value on the profit function (4.2), so that $\pi\left(E_{1}, E_{2}\right)=3672.552415$. the amount of value on the profit is the maximum profit on the harvesting business carried out. The values of $E_{1}$ and $E_{2}$ obtained are substituted into a model (2.3) with harvesting to obtain a continuous harvesting effect.

At the critical point $E_{1}$ and $E_{2}$ the equilibrium point is obtained from the model (2.3) which is the critical point, namely

$T_{5}=\left(x_{3}, y_{3}, z_{3}\right)=$

(50.04359875, 312.7724922, 1.491345852).

Meanwhile, the characteristic equation of the Jacobian matrix is

$f(\lambda)=\lambda^{3}+0.8609564703 \lambda^{2}+$ $0.08702266099 \lambda+0.00003478683043$.

The characteristic equation has eigenvalues, namely

$$
\begin{aligned}
& \lambda_{1}=-0.744063315261889, \\
& \lambda_{2}=-0.116491817718934 \\
& \lambda_{3}=-0.000 .401337319077391
\end{aligned}
$$

Eigenvalues show that the equilibrium point $T_{5}=$ $\left(x_{3}, y_{3}, z_{3}\right)$ is locally asymptotically stable. This situation provides information that over a long time the population of predators and prey continues to grow well. Therefore, the effect of harvesting efforts is to maintain the sustainability of the predator and prey population.

\section{Harvesting effect}

This section describes the initial conditions that show the condition of the population before and after harvesting. Presentation of the data will be carried out using several parameter values that have been taken at the beginning. The initial conditions taken from the model (2.3) at any time $t$ are $x(0)=20, y(0)=15$ and $z(0)=10$. The initial values represent three populations, each of which is initial prey, predator one, and predator two without harvesting and with harvesting. Furthermore, the trajectories of the three populations are presented:

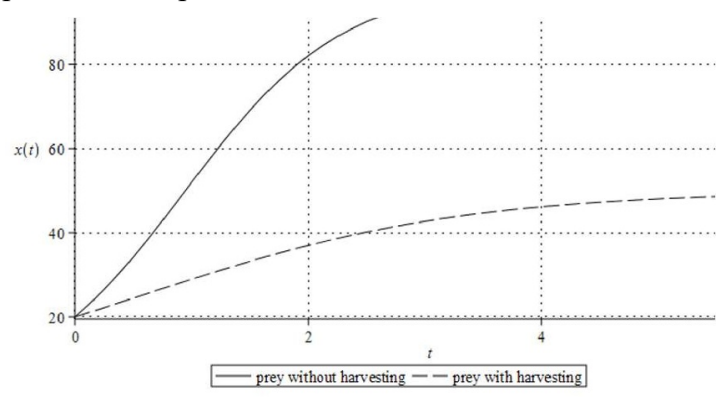

Fig. 1. Trajectories for prey without and with harvesting 


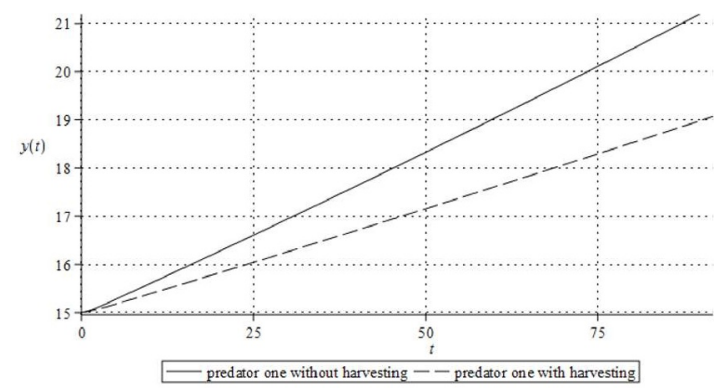

Fig. 2. Trajectories for predator one without and with harvesting

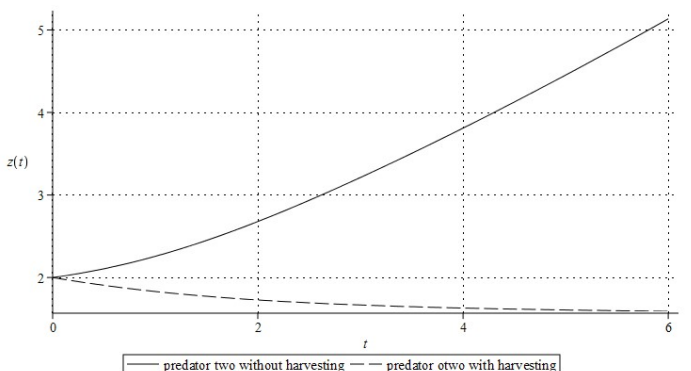

Fig. 3. Trajectories for predator two without and with harvesting

Figure 1, shows good results as the effect of harvesting. The population growth rate has decreased when compared to before harvesting. The population decline but towards the stability of population growth. Figure 2 shows good results this is due to the nonharvesting of predator one population. So that the growth curve continues to move upwards both without harvesting and with harvesting. This curve movement is very good for a long time. Figure 3 shows that the results are not very good, this is because the population growth curve at the time without harvesting continues to climb, but after harvesting the growth curve decreases. The decline in population growth rate indicates that the effect of harvesting is not optimal. If harvesting continues for a long time, the population will disappear. This destruction is certainly not expected for ecological and economic sustainability. All Trajectories images show the harvesting effect. This can be a consideration in making decisions for fishermen, government, or policymakers in exploiting marine ecosystems.

\section{Conclusions}

The schooling population model is very interesting to be used as study material in the future. This theme is following the condition of the ecosystem in nature. The population model carried out is the prey population, predator one and predator two. Also the harvesting effect is seen in depth in this study. We found five equilibrium points, but only one point is the interior equilibrium point. Numeric simulation with parameters taken from assumptions and references yields a stable local no-harvest interior equilibrium. In a model with harvesting effort, the stable equilibrium point will determine the harvesting effort and the maximum profit. From the trajectories of the prey population, the harvesting effect is a good sign for long-term harvesting. Trajectories on predator one population do not have a significant effect on population sustainability. Meanwhile, trajectories for predator population two, show poor results if harvesting continues. Continuous harvesting efforts will result in the extinction of population predator two.

\section{References}

1. Pratama, R.A., Toaha, S., Kasbawati: Optimal harvesting and stability of predator prey model with Monod-Haldane predation response function and stage structure for predator. IOP Conf. Ser. Earth Environ. Sci. 279, 0-7 (2019). https://doi.org/10.1088/1755-1315/279/1/012015

2. Partridge, B.L., Pitcher, T., Cullen, J.M., Wilson, $\mathrm{J} .:$ The three-dimensional structure of fish schools. Behav. Ecol. Sociobiol. 6, 277-288 (1980). https://doi.org/10.1007/BF00292770

3. Jiang, H.: Turing bifurcation in a diffusive predator-prey model with schooling behavior. Appl. Math. Lett. 96, 230-235 (2019). https://doi.org/10.1016/j.aml.2019.05.010

4. kasbawati: Kontrol Optimal Upaya Pencegahan Infeksi Virus Flu Burung H5N1 dalam Populasi Burung dan Manusia. JMSK J. Mat. Stat. dan Komputasi. 8, 12-24 (2011)

5. Accolla, C., Nerini, D., Maury, O., Poggiale, J.C.: Analysis of functional response in presence of schooling phenomena: An IBM approach. Prog. Oceanogr. 134, 232-243 (2015). https://doi.org/10.1016/j.pocean.2015.02.002

6. Rodriguez-Pinto, I.I., Rieucau, G., Handegard, N.O., Boswell, K.M.: Environmental context elicits behavioural modification of collective state in schooling fish. Anim. Behav. 165, 107-116 (2020). https://doi.org/10.1016/j.anbehav.2020.05.002

7. Vijayan, S., Kotler, B.P., Abramsky, Z.: A predator equalizes rate of capture of a schooling prey in a patchy environment. Behav. Processes. 138, 91-95 (2017). https://doi.org/10.1016/j.beproc.2017.02.016

8. Rectenwald, J.E., Eliason, J.L., Henke, P.K., Upchurch, G.R., Stanley, J.C.: Splanchnic vascular occlusive and aneurysmal disease. Greenfield's Surg. Sci. Princ. Pract. Fifth Ed. 75, 1629-1652 (2012)

9. Pratama, R.A., Ruslau, M.F. V., Nurhayati, Laban, S.: Analysis stability of predator-prey model with Holling type I predation response function and stage structure for predator Analysis stability of predator - prey model with Holling type I predation response function and stage structure for predator. IOP Conf. Ser. Earth Environ. Sci. 343, 8 (2019). https://doi.org/10.1088/1755-1315/343/1/012161

10. Zhang, X., Zhao, H.: Global stability of a diffusive predator-prey model with discontinuous harvesting policy. Appl. Math. Lett. 109, 106539 (2020). https://doi.org/10.1016/j.aml.2020.106539

11. Salim, K., Rita, A., Supratman, O.: Identifikasi 
Jenis Ikan (Penamaan Lokal, Nasional Dan Ilmiah) Hasil Tangkapan Utama (Htu) Nelayan Dan Klasifikasi Alat Penangkap Ikan Di Pulau Bangka Provinsi Kepulauan Bangka Belitung. Akuatik J. Sumberd. Perair. 13, 42-51 (2019). https://doi.org/10.33019/akuatik.v13i1.1107

12. Handegard, N.O., Boswell, K.M., Ioannou, C.C., Leblanc, S.P., Tjostheim, D.B., Couzin, I.D.: The dynamics of coordinated group hunting and collective information transfer among schooling prey. Curr. Biol. 22, 1213-1217 (2012). https://doi.org/10.1016/j.cub.2012.04.050

13. D'Elia, M., Patti, B., Sulli, A., Tranchida, G., Bonanno, A., Basilone, G., Giacalone, G., Fontana, I., Genovese, S., Guisande, C., Mazzola, S.: Distribution and spatial structure of pelagic fish schools in relation to the nature of the seabed in the Sicily Straits (Central Mediterranean). Mar. Ecol. 30, $151-160$ (2009). https://doi.org/10.1111/j.1439-0485.2009.00328.x

14. Toaha, S., Azis, M.I.: Stability and Optimal Harvesting of Modified Leslie-Gower PredatorPrey Model. J. Phys. Conf. Ser. 979, (2018). https://doi.org/10.1088/1742-6596/979/1/012069

15. Manna, D., Maiti, A., Samanta, G.P.: Analysis of a predator-prey model for exploited fish populations with schooling behavior. Appl. Math. Comput. 317, $35-48$

(2018). https://doi.org/10.1016/j.amc.2017.08.052

16. Al-nassir, S.: The Dynamics and Optimal Control of a Prey-Predator System. 13, 5287-5298 (2018)

17. Agus, S., Toaha, S., Kasbawati, K.: Analisis Model Populasi Mangsa Pemangsa dengan Area Reservasi dan Pemanenan Pemangsa. J. Mat. Stat. dan Komputasi. 15, 1 (2018). https://doi.org/10.20956/jmsk.v15i1.4418

18. Yan, X.P., Zhang, C.H.: Global stability of a delayed diffusive predator-prey model with prey harvesting of Michaelis-Menten type. Appl. Math. Lett. 114, $106904 \quad$ (2021). https://doi.org/10.1016/j.aml.2020.106904

19. Pratama, R.A., Ruslau, F.V.M., Suryani, D.R.: Model Matematika Kecanduan Terhadap Aibon. Axiomat. J. Mat. dan Apl. 2, 10-15 (2020)

20. Pratama, R.A., Ruslau, M.F.V., Suryani, D.R., Meirista, E.: Optimal harvesting and stability of predator-prey model with holling type II predation respon function and stage-structure for predator. J. Phys. Conf. Ser. 1569, (2020). https://doi.org/10.1088/1742-6596/1569/4/042067 